Mansoura University

Faculty of Education

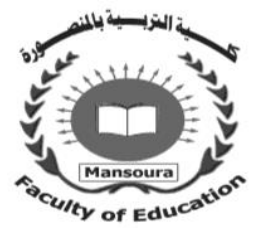

Developing EFL Students' Reading Comprehension skills through Using Transactional Literature Circles

\author{
By \\ Hend Mahmoud Ibrahim Ali
}

Superuised by

\author{
Dr. Badran A. Hassan \\ Professor of Curriculum Instruction \\ (TEFL) \\ Faculty of Education Mansoura \\ University
}

Dr. Rehab Hamadtoh Gohar Assistant Professor of Curriculum \&Instruction (TEFL)

Faculty of Education

Mansoura University

Journal Of The Faculty Of Education-Mansoura University No. 112 - Oct .2020 


\title{
Developing EFL Students' Reading Comprehension skills through Using Transactional Literature Circles
}

\section{Hend Mahmoud Ibrahim Ali}

\begin{abstract}
The present research aimed at developing the EFL Reading comprehension skills of secondary school students through using Transactional Literature Circles. It adopted a quasi -experimental design employing two groups; experimental and control. Participants were 80 first year female students enrolled at Dikirnis Secondary School for Girls, Dakahliya Governorate. Instruments included a Reading Comprehension Skills Checklist (RCSC) and a Reading Comprehension Skills Test (RCST). The results revealed that there was a statistically significant difference between the mean score of the experimental and control groups on the post (RCS test) in favor of the experimental group. Further, the experimental group students performed better in most of the reading comprehension skills on the post test. These results generally validate the effectiveness of transactional literature circles in developing the experimental group pupils' reading comprehension skills. finally it was recommended that transactional literature circle strategy is effective in developing students' reading comprehension skills.

groups $(N=70)$. The program lasted for 6 weeks (2 sessions per week, 45 min.
\end{abstract}

\section{1- Introduction:}

Comprehension is one of the most important aspects of reading. Without comprehension, learners will not be taking any knowledge and information away from the text ( Van Keulen, 2011). Harvey and Goudvis (2007) emphasized that "when it comes to reading, it's the most important thing. If the purpose for reading is anything other than understanding, why read at all?" (p. 13). To comprehend, a reader must have a wide range of capacities and abilities that include: attention, memory, critical analytic 
ability, inferring, visualization ability, motivation and knowledge of specific.

The present researcher indicate that students in EFL classrooms still receive ineffective reading comprehension instruction. Therefore, it will be beneficial to investigate new reading comprehension instructional strategies to be used in developing students' EFL reading comprehension skills through providing students with opportunities to practice multiple reading comprehension strategies in order to help them comprehend and interact with the texts they read. Transactional Strategies Instruction (TSI), one form of comprehension instruction, has shown hope in the field of teaching reading comprehension (National Reading Panel, 2000).

Harries and Hodges (1995) define the Transactional Theory as "the view that meaning is constructed in communication through language by an active, fluid interchange of ideas within a given context, as between speaker and audience"(p.259). The name of this reading theory is inspired by the work of louise Rosenblatt (1978), who explains reading as a transactional process that occurs between the text and the reader. However, Reutzel, Smith and Fawson (2005) described transactional strategies more broadly as "a 'family' or 'set' of comprehension strategies embedded in a collaborative, interactive and engaging routine". Under this definition, models such as literature circles would be classified as Transactional Strategies Instruction(TSI). Literature circles use another kind of collaborative routine with a small group format for a student-led literature discussion.

The transactions that exist within the literature circles are among the learner, the teacher and the text. These interactions are dynamic and synergistic. They promote and construct genuine relationships within the classroom community. The learner brings both language and culture to the literature circle. The learner becomes an interactive agent in learning when relating to his or her teacher, peers and text. All learners are encouraged to build bridges of understanding using the socialisation patterns that are familiar in the home language and culture. These bridges become useful in motivating their learning ( Banks, 2003).

\section{Review of literature}

\section{The Transactional Theory}

The name of this reading theory is inspired by the work of Rosenblatt (1978) cited in (church ,1997), who explained reading as a transactional process that occurs between the text and the reader. This concept provides a 
flexible framework for engaging learners in a process of active and personally meaningful interaction with the text.

Rosenblatt transactional theory involves a transaction between the reader and the text; this transaction produces meaning within that readertext interaction. Each reader brings individual background knowledge, beliefs, and context to the reading event. As a result, any given text has as many different meanings as there are readers. Rosenblatt's work led directly to reader-response theory, in which the reader, an active agent, completes the meaning of a text through engagement and interpretation (Fish, 1967). Thus, the reader response theory can be considered as the basis of the transactional theory.

\section{Transactional Theory and Reader Response Theory}

Rosenblatt (1978) has caused us to pay attention to the role of reader in reading. She envisioned the aim of literature education as growth in experience rather than the means to acquiring knowledge. Her theory centered on the reader's role in the transactional relationship with the text.

The reader response theory, as a philosophy of teaching the literacy work, investigates the interaction between the text and the reader by highlighting the affective and cognitive processes of understanding and enjoyment, while acknowledging that different viewpoints exist in the literature (Sfo, 2003).

Brassell \& Rasinski (2008) supports the reader-response theory, in which students give opinion and criticism, make inferences and judgment, ask personal question, make connection (text to self-connection, text to text connection and text to world connection), and create ongoing summaries and synthesis as they read.

\section{Transactional Strategy Instruction (TSI) and literature circles}

TSI has a lot in common with literature circles, but it is a significantly more structured intervention. TSI takes into account that meaning is determined through the interaction of prior knowledge and information conveyed through text, and that one student's reaction is influenced by what other group members do, think, and say. Like literature circles, TSI is made up of teacher-facilitated student discussions, and the meaning that emerges is the product of the group's interactions. Unlike literature circles, a set of comprehension strategies are explicitly taught and modeled by the teacher: making connections, asking questions, inferring, visualizing, determining importance, synthesizing, and Summarization. While the approach to facilitating a literature circle is relatively minimalist, the role of the teacher in TSI is very active, in a clear expert role, and requires extensive training, 
though the teacher role diminishes over time as children master the strategies (Pressley et al., 1992; McElvain, 2010).

\section{Literature circles}

Daniels (1994) has been a firm believer in the benefits of incorporating literature circles into classroom instruction. He defined literature circles as "Literature circles are small, temporary discussion groups who have chosen to read the same story, poem, article, or book. Each member prepares to take specific responsibilities in the upcoming discussion, and everyone comes to the group with the notes needed to help perform that job" (p.13).

According to Byrd (2002), literature circles offer cognitive, affective, and social benefits to developmental reading learners. Learners coconstructed meaning through connections with self, others, and texts. Finally, interaction patterns support the suggestion that learners need the opportunity to engage in "grand conversations" in order to better understand text and self .

According to Ruthrford (2009), many learners do not read so it is necessary for teachers to utilize instructional practices that promote reading for pleasure and at the same time engage learners in meaningful and thoughtful reading. One exciting instructional strategies that encourage active participation in literary text in a meaningful and enjoying manner is literature circles.

Daniels (2002) believed that ideal literature circles involve small temporary groups of learners who chose to read the same text, meet regularly to discuss their reading, assumes specific rotational roles as they prepare for the discussion. When a text is completed, groups find ways to communicate their discussion to other classmates and then they form new groups around new books.

\section{Literature circles roles}

Literature circles are an ideal example of a literacy event that allows participants to be involved in a social activity around a piece of literature and offer opportunities for participants. According to Daniels (1994), the various literature circle roles offer a strategic approach to help learners make meaning of texts. Learners reflect on what they have read and engage in meaningful conversations about texts that are of interest to them, among roles commonly assigned to learners are:

The first role is the discussion director: in charge of completing assessment of the work accomplished by the group and keeps the group on 
task and moderates the conversation so that all group members have a chance to speak and to share their ideas.

The second role is the connector: find connections between the book that group is reading and the world outside.

The third role is the vocabulary enricher: lookout for a few especially important words in the text, find words that are puzzling or unfamiliar and then later jot down their definition, either from a dictionary or from some other source.

The fourth role is the travel tracer. When learners are reading a book in which characters move around often and the scene changes frequently, it is important for everyone in the group to know where things are happening and how the setting may have changed.

The fifth role is summarizer. prepare a brief summary of what they have already read.

The sixth and final role is the investigator. dig up some background information on any topic related to text.

\section{Teacher's Role in Literature Circles}

Stein and Bede (2004) has stated the roles that teachers play within literature circles. Identified four roles that teachers take on during these discussion groups : facilitator, participant, mediator, and active listener.

The first role is facilitator involved the teachers encouraging learners' interaction and talk and to monitor social interactions which interfered with discussion.

The second role looked at the teacher as a participant. This involved teachers interacting as readers by sharing personal connections, opinions, ideas, and questions that stemmed from their personal understanding of the book.

The third role identified the teacher as a mediator. This role involved teachers using facilitator or participant talk to encourage learners to connect their discussions about the book to their own life experiences, beliefs and values.

The final role is active Listener. This role moved away from teacher dominated discussions and left the control up to group negotiation.

Features of Literature Circles 
Daniels (2002) listed some features of literature circles and indicated that each of these features was equally important to the success of literature circles, that include the following:

1. Students choose their own reading materials.

2. Small temporary groups are formed based on book choice.

3. Different groups read different books.

4. Groups meet on a regular, predictable schedule to discuss their reading.

5. Students use written or drawn notes to guide both their reading and discussion.

6. Discussion topics come from students.

7. In newly-formed groups, students play a rotating assortment of task roles.

8. The teacher serves as a facilitator, not a group member or instructor.

9. Evaluation is by teacher observation and student self-evaluation.

10.When books are finished, readers share with their classmates, and new groups are formed.

\section{Literature Circles and reading comprehension}

Literature circles are designed to strengthen reading comprehension skills (Huber, 2001). Kasim (2011) has stated that co-operative learning is a successful teaching strategy in which small teams, each with learners of different levels of ability, use a variety of learning activities to improve their understanding of a subject.

Furr (2004) has stated that EFL literature circles are fun, focused classroom based learner reading and discussion groups. In short, the teacher can present an interesting reading for learners and choose the material that increases their motivation to study. The strategy benefits not only the group but also each individual learner; it increases the amount of reading learners do, provides opportunities for inquiry and critical thinking, and teaches learners how to work together co-operatively.

\section{The benefit of literature circles in teaching reading comprehension}

Lin (2004) listed the benefits of literature circles which some studies have been identified by some studies as follows:

(a) Stronger reader-text relationships.

(b) Improved classroom climates.

(c) Enhanced degrees of gender equity and understanding.

(d)The learning environment more conducive to the needs and abilities of English language learners.

\section{Reading comprehension}


Comprehension is a complex process that demands much from the reader. The National Reading Panel (NRP, 2000) considered comprehension as the intentional thinking during which meaning is constructed between the reader and text. This implies that the reader interacts with the text content, using his or her vocabulary, background knowledge, motivation to read that text, knowledge of text structure, and strategies to construct meaning. Reading comprehension process

\section{Before Reading Stage}

Learning happens when learners are interacting cooperatively with their peers in their own environment (Wei-Fan, \& Chung-Pei, 2011). Teachers need to take into consideration the prior knowledge learners have from home and peers, and use it to help their learners comprehend successfully.

\section{During Reading Stage}

During the reading process, Hedge (2003) argued, learners should be required to continually practice and apply the comprehension strategies that good readers employ almost subconsciously, such as making connections, monitoring understanding, stopping to summarize, asking questions, etc.

\section{Post Reading Stage}

During the after reading stage, learners articulate and process their understanding of what they have read and think critically about the validity of the text. Huber (2003) ) stated that the stage of the reading process after learners have read is ripe with opportunities to build learners' metacognitive muscles in these areas.

\section{Models of reading comprehension process \\ The Bottom-up Model}

bottom-up reading model is a model that focuses on a single-direction, part-to-whole processing of a text. James \& Gentry (2008) explained that the bottom up model involves a series of steps that the reader has to go through the smallest linguistic units such as: sentences, phrase, and so on, until reaching the meaning of the text.

\section{The top-down model}

A top-down reading model is a model that focuses on what the reader brings to the text to arrive at the meaning.

According to this model, what readers bring to text is more important than what the text brings, so it contrasted with the bottom-up model, because it emphasizes "from brain to text" (Eskey, 2005, p. 564).

\section{The Interactive model}


Rumelhart (1977) offered an interactive model of reading which is a combination of both top-down and bottom up strategies. This model is now widely considered a comprehensive explanation of how we derive the meaning of a written text. He developed this model based on the fact that meaning does not reside in the text alone, but is a co-construction of the writer's text and the reader's interpretation. So, reading needs an interaction between the reader's mind and the writer's text. This allows the information contained in higher stages to interact with and influence the information in lower stages.

\section{Assessment of reading comprehension}

Black \&William (1998) defined assessment as the practice of detecting and defining the students' knowledge, understandings, abilities, and skills. It is a classroom activity used to stimulate learning by collecting data and offering constructive feedback.

\section{Types of Assessment}

Habib (2016) states that there are three main types of assessment which occur in different times, at different levels, and in different forms to achieve multiple purposes.

\section{Diagnostic Assessment}

Diagnostic assessment is the process of diagnosing learners strengths and weaknesses at the beginning of a course.

\section{Formative Assessment}

Formative assessment characterized by its progressive nature as it can happen at any period of time. It also can be planned or unplanned, proactive or reactive, formal or informal involves designing goals, providing instruction, measuring outcomes, and giving useful feedback. Actually, it includes the process of appraising, evaluating students performance and using this to shape and improve learners competence.

\section{Summative Assessment}

Summative assessment provides evidence of what students got at the end of a specific term of learning. Furthermore, it marks the important stages of students development and should be formally recorded in the form of scores and marks. It is carried out at the end of a period of instruction so that to make clear judgments about where students are successful and where they are not in any area of knowledge.

\section{Related Studies}


El-Maleh (2006) investigated the effectiveness of proposed literature circles program on developing critical reading to secondary school students through teaching short story. The sample was 99 students. The instruments were the needed critical reading skills questionnaire, the pre/post critical reading skills test, the LC students' satisfaction/dissatisfaction questionnaire and the LC teacher's guide questionnaire and the proposed LC teacher's guide itself. The results indicated that a significant improvement in the level of the experimental group students was obtained when comparing students' pre-scores to their post scores.

McElvain (2010) examined a problem that many teachers face today: how to successfully improve reading comprehension for English language learners (ELLs). The researcher examines both the academic and psychosocial effects of the Transactional Literature Circles (TLC) program on a treatment group of 75 fourth to sixth grade. The results of this study reported that TLC positively affected the reading comprehension of the programme participants. The students in the TLC program outperformed the students in the control group on standardised reading tests.

Ahmed (2018) conducted a study aimed at investigating the effectiveness of using literature circles strategy for developing secondary stage students' reading comprehension skills and attitudes toward studying English . The sample of the study consisted of 80 students. The instrument were a checklist and a pre-post reading comprehension skills test. The results of the study revealed that there were statistically significant differences at 0.05 level between the mean scores of the control and the experimental groups on the post- test, in favor of the latter concerning overall reading comprehension as well as each single reading comprehension sub-skill.

\section{Statement of the problem}

Based on the previous literature, the researcher 's experience and the results of the pilot study, secondary stage students' level need to improve their reading comprehension skills. Students have lots of problems with reading a text which was obvious in some of their reading skills Thus, the present study investigated the effectiveness of using transactional literature circles on developing secondary school students EFL reading comprehension skills.

\section{Research Questions}

The present study attempted to find answers to the following question: 
What is the effectiveness of using transactional literature circles in developing first year secondary school students' required EFL reading comprehension skills?

Three sub- questions were derived from the main question:

1- What are the reading comprehension skills that need to be developed for the secondary school students?

2- What are the features of the transactional literature circles?

3- What is the effect of transactional literature circles on developing first year secondary school students' each of EFL reading comprehension skills?

\section{Purpose}

The present study aimed at:

- Identifying the EFL reading comprehension skills necessary for the $1^{\text {st }}$ year secondary school students .

- Determining the features of transactional literature circles for developing the reading comprehension skills.

- Investigating the effectiveness of Transactional Literature Circles in developing reading comprehension skills of first year secondary student.

- Developing the participants' reading comprehension skills.

\section{hypotheses}

The study aimed at testing the following hypotheses:

1- There is a statistically significant difference at the.05 level between the mean score of the experimental group and that of the control group on the reading comprehension post-test in favor of the experimental group.

2- There is a significant statistical difference at 0.05 level between the mean scores of the experimental group on the pre-post reading comprehension skills test in favor of the post application.

\section{Significance}

This study could be significant in a number of ways:

- Developing the reading skills of secondary school students.

- Drawing the attention of teachers to the possible positive effects of using literature circles.

\section{Methods}

\section{Participants:}


The participants of this study were selected from the first year secondary school Modern Secondary School in Dikernis, Dakahlia Governorate, in the 2019/2020 academic year. Their ages ranged from sixteen to seventeen years old. They were assigned to two groups an experimental group and a control one. Each group consisted of 40 female students.

\section{Setting}

The experiment took place in Modern Secondary School for Girls in Dikirnis, Al-Dakahlia Governorate. Two classes of first year secondary students were selected for the experimentation of the study. This was done during the first semester of the 2019/2020 academic year for nine weeks during October and November.

\section{Instruments of the Study}

The researcher used the following instruments in this study:

1- A reading comprehension skills checklist to identify the reading comprehension skills necessary for students to help them comprehend the reading passages in their textbook reading passages.

2- A reading comprehension test in order to determine the effectiveness of using transactional literature circles in developing students' reading comprehension.

\section{Definition of Terms}

\section{- I Transactional Strategy Instruction}

According to Pressley, El-Dinary, Gaskins, Schuder, Bergman, Almasi, \& Brown (1992), transactional strategy instruction is a complex instructional process for teaching students to use multiple comprehension strategies flexibly and interactively around text to increase both their selfregulated strategy use and understanding of text.

\section{Literature circles:}

Literature circles are small, student-led discussion groups in which members read the same book. Group members take on various 'roles' that guide the reading and the discussion. Group members are asked to prepare for and contribute to the discussion. Each group member becomes an expert at his or her assigned role (Daniels, 2002).

Literature circles are a student driven strategy which places students at the centre of instruction by giving them opportunity to take ownership of their learning through freedom to choose what to read; how to read; when and where to read. Students share and discuss chosen texts in social groups. Hence, power and control are taken from teachers and given to students 
thereby, disrupting and destabilizing the traditional teacher - centred literacy practices' (Holly, 2010).

The current study defines Transactional Literature circles as a practice that small groups of learners meet regularly to discuss and respond to texts that they are all reading. Each member agrees to take specific responsibilities and roles at each meeting. In literature circles, the learners' inquires and thoughts drive the discussion in an effort to construct meaning and enhance understanding. As a result, discussions occur among the learners, ideas are transformed, renewed, and eventually internalized by the participants.

\section{2-Reading Comprehension}

Reading comprehension according to snow (2003) is "The process of simultaneously extracting and constructing meaning through interaction and involvement with written language. It consist of three elements: the reader, the text , and the activity or purpose for reading"(p.11).

Reading comprehension is the "interaction among word identification, prior knowledge, comprehension strategies, and engagement" (Prado \& Plourde, 2005, p. 33).

The current study defines reading comprehension as the ability to read a text, process it and understand its meaning via using transactional literature circles strategy.

\section{Result and discussion}

\section{Testing the First Hypothesis}

The first hypothesis stated that: "There is a statistically significant difference at the.05 level between the mean score of the experimental group and that of the control group on the reading comprehension post-test in favor of the experimental group".

To verify this hypothesis, the researcher used the t-test for independent samples. See table (1): 
Table (1)

Comparing the reading performance of the control and experimental groups on the post-administration .

\begin{tabular}{|c|c|c|c|c|c|c|c|}
\hline Sig. (2-tailed) & $\begin{array}{c}D f(\mathrm{n} 1+\mathrm{n} 2- \\
2) \\
\end{array}$ & $T$ & $S D$ & Mean & $N$ & Group & Stages \\
\hline \multirow{8}{*}{$\begin{array}{l}\text { Significant at } \\
0.05\end{array}$} & \multirow{8}{*}{78} & \multirow{2}{*}{14.5} & 1.91469 & 5.9750 & $\varepsilon$. & Control & \multirow{2}{*}{ Literal comprehension } \\
\hline & & & 1.18078 & 11.1250 & $\varepsilon$. & Exp. & \\
\hline & & \multirow{2}{*}{17.2} & 1.62038 & 5.2000 & $\varepsilon$. & Control & \multirow{2}{*}{ Inferential comprehension } \\
\hline & & & 1.39596 & 11.0000 & $\varepsilon$. & Exp. & \\
\hline & & \multirow{2}{*}{10.6} & 1.97273 & 5.4250 & $\varepsilon$. & Control & \multirow{2}{*}{$\begin{array}{l}\text { Critical /Evaluative } \\
\text { comprehension }\end{array}$} \\
\hline & & & 3.71380 & 12.4500 & $\varepsilon$. & Exp. & \\
\hline & & \multirow{2}{*}{18.3} & 3.26442 & 16.6000 & $\varepsilon$. & Control & \multirow{2}{*}{ Total } \\
\hline & & & 0, YVIO & $r \leqslant, 0 \vee 0$. & $\varepsilon$. & Exp. & \\
\hline
\end{tabular}

A t-test for independent samples was used to compare the mean score of the control and experimental groups. Table (1) shows that the mean scores of the experimental group students in the three domains (Literal comprehension, Inferential comprehension and Critical /Evaluative comprehension ) and in the total were higher than those of the control group. The table illustrates also that the estimated t-value is significant at .05 level. This indicates that there are statistically significant differences between the experimental and control groups in the three domains and in the total score on the post-reading comprehension test. These significant differences are in favor of the experimental group. In other words, the experimental group outperformed the control group in their EFL reading comprehension skills of the identified domains (Literal comprehension,

Inferential comprehension and Critical /Evaluative comprehension ) .

\section{Estimate the effect size ( $\eta 2)$ :}

Eta Square $(\eta 2)$ was used in order to estimate the effect size of the experimental treatment. Table (2) shows the results.

Table (2)

The effect size of using the transactional literature circles on the reading comprehension skills of the experimental group

\begin{tabular}{|c|c|c|c|c|c|c|}
\hline $\begin{array}{l}\text { Level of } \\
\text { Effect Size }\end{array}$ & $\begin{array}{l}\text { Value of Eta- } \\
\text { square ( } \eta 2)\end{array}$ & $\begin{array}{l}\text { D. f } \\
(n-1)\end{array}$ & $\mathbf{T}$ & Dom & ns of the dependent variable & Independent variable \\
\hline \multirow{4}{*}{ High } & \multirow{2}{*}{\multicolumn{2}{|c|}{0.73}} & \multirow{4}{*}{78} & 14.5 & Literal comprehension & \multirow{4}{*}{$\begin{array}{l}\text { The Transactional } \\
\text { Literature Circles } \\
\text { strategy }\end{array}$} \\
\hline & & & & 17.2 & Inferential comprehension & \\
\hline & \multicolumn{2}{|l|}{0.57} & & 10.2 & $\begin{array}{l}\text { Critical /Evaluative } \\
\text { comprehension }\end{array}$ & \\
\hline & \multicolumn{2}{|l|}{0.81} & & 18.3 & Total score & \\
\hline
\end{tabular}


Results in the previous table reflect that the effect size of the transactional literature circles strategy on the experimental group students in the three domains of EFL reading comprehension skills (Literal comprehension, Inferential comprehension and Critical /Evaluative comprehension ) is high. This result can be illustrated similarly as follows:

- $73 \%$ of the total variance of the first domain (Literal comprehension) of the dependent variable can be attributed to the independent variable (TLC strategy).

- $79 \%$ of the total variance of the second domain (Inferential comprehension) can be attributed to the proposed strategy.

- $57 \%$ of the total variance of the third domain (Critical /Evaluative comprehension) can be attributed to the proposed strategy.

- $81 \%$ of the total variance of the overall reading comprehension test can be attributed to the independent variable (the TLC strategy ).

The significant differences between the experimental and control groups shown in table (1) in addition to the effect size results shown in table (2) support the effectiveness of the transactional literature circles strategy in developing EFL reading comprehension skills for first year secondary stage students; and this effect is in favor of the experimental group. Consequently, the first hypothesis of the study is accepted.

\section{Testing the Second Hypothesis}

The second hypothesis stated that: "There is a significant statistical difference at 0.05 level between the mean scores of the experimental group on the pre-post reading comprehension skills test in favor of the post application".

To verify the second hypothesis, the researcher used the t-test for paired samples. See table (3): 
Table (3)

Comparing the reading comprehension skills of the experimental group on the pre-post administration.

\begin{tabular}{|c|c|c|c|c|c|c|c|}
\hline Sig. (2-tailed) & $\begin{array}{c}D . f \\
(n-1)\end{array}$ & $T$ & $S D$ & Mean & $N$ & $\begin{array}{c}\text { Measure- } \\
\text { ment }\end{array}$ & Domains \\
\hline \multirow{8}{*}{$\begin{array}{l}\text { Significant at } \\
0.05\end{array}$} & \multirow{8}{*}{39} & \multirow{2}{*}{22.3} & 1.37724 & 4.4750 & 40 & Pre & \multirow{2}{*}{ Literal comprehension } \\
\hline & & & $1,1 \wedge \cdot \gamma \wedge$ & $11,1,0$. & $\varepsilon$. & Post & \\
\hline & & \multirow{2}{*}{19.1} & 1.88380 & 4.3000 & $\varepsilon$. & Pre & \multirow{2}{*}{ Inferential comprehension } \\
\hline & & & $1, r 9097$ & $11, \ldots$ & $\varepsilon$. & Post & \\
\hline & & \multirow{2}{*}{13.9} & 1.89043 & 3.3750 & $\varepsilon$. & Pre & \multirow{2}{*}{$\begin{array}{l}\text { Critical /Evaluative } \\
\text { comprehension }\end{array}$} \\
\hline & & & r,virA. & Ir, $\{0 \ldots$ & $\varepsilon$. & Post & \\
\hline & & \multirow{2}{*}{21.2} & 4.04811 & 13.8500 & $\varepsilon$. & Pre & \multirow{2}{*}{ Total } \\
\hline & & & $0, Y Y \backslash 0 \varepsilon$ & $r \varepsilon, 0 \vee 0$. & $\varepsilon$. & Post & \\
\hline
\end{tabular}

Results in the above table illustrate that the estimated t-value is significant at 0.05 level. This reflects that there are statistically significant differences between the mean scores of the pre-post-administration of the reading comprehension test in the three domains and in the total score. These significant differences are in favor of the post-test.

\section{Estimating the effect size ( $\boldsymbol{\eta} 2)$ :}

Table (4) illustrates the effect size of the transactional literature circles strategy concerning the difference between the pre- and post- Reading Comprehension test on the experimental group.

\section{Table (4)}

The effect size of using the transactional literature circles on the reading comprehension skills of the experimental group

\begin{tabular}{|c|c|c|c|c|c|c|}
\hline $\begin{array}{l}\text { Level of } \\
\text { Effect Size }\end{array}$ & $\begin{array}{l}\text { Value of Eta - } \\
\text { square ( } \eta 2)\end{array}$ & $\begin{array}{l}\text { D. f } \\
(n-1)\end{array}$ & $\mathbf{T}$ & $\begin{array}{l}\text { Dom } \\
\text { varia }\end{array}$ & $\begin{array}{l}\text { ns of the dependent } \\
\text { le }\end{array}$ & Independent variable \\
\hline \multirow{4}{*}{ High } & \multicolumn{2}{|l|}{0.93} & \multirow{4}{*}{39} & 22.3 & Literal comprehension & \multirow{4}{*}{$\begin{array}{l}\text { the Transactional } \\
\text { Literature Circles }\end{array}$} \\
\hline & \multicolumn{2}{|l|}{0.90} & & 19.1 & $\begin{array}{l}\text { Inferential } \\
\text { comprehension }\end{array}$ & \\
\hline & \multicolumn{2}{|l|}{0.83} & & 13.9 & $\begin{array}{l}\text { Critical /Evaluative } \\
\text { comprehension }\end{array}$ & \\
\hline & \multicolumn{2}{|l|}{0.92} & & 21.2 & Total score & \\
\hline
\end{tabular}

Table (4) illustrates the effect size of the transactional literature circles strategy on the experimental group students in the three domains of EFL Reading comprehension skills. Results indicated that the effect size is high in the three domains. This difference between the pre- post test can be illustrated similarly as follows:

$1.93 \%$ of the total variance of experimental group students' post- test in the first domain (literal comprehension) of the dependent variable can be attributed to the independent variable (the transactional literature circles). 
$2.90 \%$ of the total variance of the second domain (Inferential comprehension) can be attributed to the independent variable (the transactional literature circles).

$3.83 \%$ of the total variance of the third domain(Critical /Evaluative comprehension) can be attributed to the independent variable (the transactional literature circles).

$4.92 \%$ of the total variance of the three domains of the dependent variable of the can be attributed to the independent variable (the transactional literature circles).

Results in tables (3) and (4) prove that the statistical differences between the pre- post reading comprehension test are in favor of the posttest. In addition, the size of these differences fosters the positive effect of the strategy of transactional literature circles. Therefore, the second hypothesis of the study is proved and accepted.

\section{Discussion of the results:}

The previously mentioned results indicate that both individually and as a group students' reading comprehension scores increased through their participation in transactional literature circles. Through discussion and their role sheets, they were able to understand the text.

Transactional literature circles strategy is an effective literacy strategy that combines the principles of cooperative learning, independent reading and group discussion. The purpose of transactional literature circles is to promote reading and to foster literary discussions. Daniels' (2002) research linked literature circles with an increase in reading comprehension. This study's findings also show an increase in reading comprehension of text due to the implementation of literature circles. This was made evident by the improvement of the students' reading comprehension test scores.

Results of the current study add up to those of the previous studies of El-Maleh 2006, McElvain 2010, Ahmed 2018, which reported that the transactional strategies were effective in developing students' reading skills. The previous studies investigated different methods and strategies, different school levels and grades in improving reading comprehension and all these studies proved the effectiveness of these approaches and strategies in improving reading comprehension. Obtained results from this current study goes in line with McElvain (2010) results that TLC positively affected the reading comprehension of the program participants. The 
students in the TLC program outperformed the students in the control group on standardised reading tests and the reading comprehension improved significantly.

It can be stated that transactional literature circles allow students to have a voice inside the classroom and create an environment in which they co-operate with each other in their own learning and reading. There were a variety of strategies used to enhance the anticipated reading comprehension skills. Students got involved in groups of six members each. These groups formed the Reading Circles. The reading circle strategy was the principal strategy used by students throughout the strategy. Students were assigned functional roles (6) and learning roles. The researcher sometimes used modeling and think aloud strategies to introduce new skills. Students also got involved actively in reading activities such as different reflection worksheets, exercises, oral questions, and assignments and they performed together. Students completed activities based on their specific role and took notes to help facilitate discussion. Students showcased their notes after they have read and discussed the text. Students chose the way in which they presented the text. At the same time, the researcher had a checklist for each circle in each activity. These checklists were used as a formative assessment to judge whether the majority of the class could determine the reading comprehension skills. The back of the checklist provided a space for the teacher to record observations and information about how the circles worked together. The teacher could record his own observations as well as what the circles shared with the class.

This environment helps them feel accepted as part of a peer group. Also, transactional literature circles allow students to produce critical thinking skills due to the fact that they are in charge of their own learning. Further, it is this ownership that allows students to think for themselves rather than receiving the answers or interpretations from the teacher. In transactional literature circles, struggling readers may well come to recognize that reading no longer means having the right answer or pronouncing every word correctly, but instead making meaning of the text and connecting it to her/his own life. Thus, the research suggests that transactional literature circles constitute a strategy to help struggling readers become engaged and reflective. 
Based on the analysis of the study results and the discussion mentioned above, it can be concluded that using the TLC strategy has a high effect on enhancing and improving significantly secondary stage students' reading comprehension .

\section{Recommendations of the Study}

Based on the results and conclusions of this study, the following recommendations were offered:

1. Transactional literature circles strategy instruction is recommended as a teaching learning technique in order to enable students to construct meaning from the reading texts throughout developing their reading comprehension skills.

2. Curriculum designers and EFL instructors should include more interactive teaching strategies such as TLC, which concentrate on the students' understanding instead of focusing only on students' memorizing the questions and answers for the final exams.

3- EFL course designers and instructors need to develop the way they teach reading texts. Innovative techniques that aim at motivating learners to read and comprehend what they read should be used. Teachers should use new teaching strategies and liberate themselves from conventional teaching practices especially in reading comprehension instruction.

4- To effectively deal with reading texts, good classroom instruction should include interaction with texts, opportunities for students to share ideas, participation in activities with each other and their teacher and student-centered classroom where the teacher's role is minimized to be a planner, a facilitator and a guide.

\section{References}

Ahmed, S. (2018). A proposed program Based on Literature Circles for Developing Secondary Stage Students' Reading Comprehension Skills and Attitudes Toward Studying English . [Unpublished master's thesis]. Damietta University.

Banks, J. \& Banks, C. (2003). Multicultural education: Issues and perspectives. (4th edn). Hoboken, NJ: John Wiley \& Sons Inc.

Black, P., \& William, D. (1998). Assessment and Classroom Learning. Assessment in Education: Principles, Policy and Practice, 5(1): 7, 74 .

Brassell, D. \& Rasinski, T.( 2008). Comprehension that Works; Taking Students Beyond Ordinary Understanding to Deep Comprehension. Huntington Beach, CA: Shell Education. 
Byrd, D. E. (2002). An Examination of How Adult Developmental Reading Students Socially Construct Meaning While Engaged in Literature Circles. (Unpublished doctoral dissertation). Available from Pro Quest Dissertations and Theses database. Retrieved from http://search.proquest.com.ezproxy.mtsu.edu. University of Texas at Austin, Austin, TX. 3108477.

Church , G.W.(1997).The Significance of Louise Rosenblatt on the field of Teaching Literature . Retrieved May 22, 2008, from http://www.Vccaedu. org

Daniels, H. (1994). Literature Circles: Voice and choice in the student centered classroom. York, Maine: Stenhouse Publishers.

Daniels, H. (2002). Literature Circles: Voice and Choice in Book Clubs and Reading Groups. York, ME: Stenhouse Publishers.

El-Maleh, A. (2006) A Proposed Literature Circles Program for Teaching Short Story to Secondary School Students and its Effect on Third Critical Reading. [ Un published thesis (Ph. D.)]. Suez Canal University.

Eskey, D.E. (2005). Reading in a second language. In E. Hinkel (Ed.), Handbook of research in second language teaching and learning (pp. 563-580), Mahwah, NJ: Lawrence Erlbaum.

Fish, S. (1967). Surprised by Sin: The Reader in Paradise Lost. Cambridge, MA: Harvard University Press.

Furr, M. (2004). Why and how to use EFL literature circles. Retrieved January 23rd, 2014 from http://www.eflliteraturecircles.com/howandwhy2.html.

Habib, M. (2016). Assessment of Reading Comprehension. Revista Romaneasca pentru Educatie Multidimensionala,8(1), 125-147. doi: http://dx.doi.org/10.18662/rrem/2016.0801.08

Harris , T.L. \& Hodges, R.E.(1995). The literacy Dictionary. USA: International Reading Association .

Harvey, S., \& Goudvis, A. (2007). Strategies That Work: Teaching Comprehension for Understanding and Engagement (2nd ed.). Portland, ME: Stenhouse Publishers.

Hedge, T. (2003). Teaching \& learning in the language classroom. UK: OUP. Retrieved on August 1st, 2014, from http://www.photobus.co.uk/dstory_pages/what_dstory.html 
Holly, T. (2010). Literature Discussion Groups and Reading Comprehension MA.ED. Thesis. Northern Michigan University.

Huber, M. (2003). When Kids Can’t Read: What Teachers Can Do. Portsmouth, NH: Heinemann, 2003, p. 140.

James. E \& Gentry. (2008). Reading Models. Retrieved from Balancing Act:http://www.learningwithjamesgentry.com/Reading\%20Models.ht ml.

Kasim, U. (2011). An overview of the implementation of cooperative learning. English Education Journal, 2, 2-5.

Lin, C. (2004). Literature circles. Teacher Librarian, 31, 23-26.

McElvain, C. (2010). Transactional literature circles and the reading comprehension of at-risk English learners in the mainstream classroom, PhD. Thesis . University of San Francisco

National Reading Panel (2000). Comprehension III teacher preparation and comprehension strategies instruction. (Chap.4). Retrieved from http://www.nichd.nih.gov/publications/nrplch4- 111.pdf

Prado, L., \& Plourde , L. (2005). Increasing reading comprehension through the explicit teaching of reading strategies: is there a difference among the genders?. Reading Improvement, 32-43.

Pressley, M., El-Dinary, P. B., Gaskins, I., Schuder, T., Bergman, J. L., Almasi, J., \& Brown, R. (1992). Beyond direct explanation: Transactional instruction of reading comprehension strategies. Elementary School Journal, 92, 513-555.

Reutzel, D .R, Smith , J.A. \&Fawsan, P.C.(2005). An evaluation of two Approaches for Teaching Reading Comprehension Strategies in the primary Year Using Science Information Texts. Early Childhood Research Quarterly,(20),276-305.RetrivedMay22,2008,from http://www.coe.usu.edu/ecc

Rosenblatt, L. M. (1978). The reader, the text, the poem: The transactional theory of the literary work. Carbondale: IL: Southern Illinois University Press.

Rumelhart, D. E. (1977). Toward an interactive model of reading. In S. Dornic (Ed.), Attention and performance Hillsdale, NJ: Laurence Erlbaum Associates. 
Rutherford (2009) Promoting Intrinsic Reading: Implementing Literature Circles with Intermediate grade students and Pre-service Teachers. The International Journal of the Book 6.4: 246-253

Sfo, P.P.(2003).Toward A Reader- Text- Context Theoretical Model for Reading the Literary Work. Unpublished doctoral dissertation, University of Massachusetts Lowell.

Snow, C. E. (2003). Assessment of reading comprehension: Researchers and practitioners helping themselves and each other. In Sweet, A. P. and Snow, C. (eds.) Rethinking Reading Comprehension, pp 192-206. New York: Guilford.

Stein, D., \& Bede, P. L. (2004). Bridging the gap between fiction and nonfiction in the literature circle setting. The Reading Teacher, 57(6), $510-518$.

Van Keulen, B, J.(2011). Effects of Literature Circles on Comprehension and Engagement. Southwest Minnesota State University, Unpublished Dissertation.

Wei-Fan, C., \& Chung-Pei, C. (2011). Effect of varied types of collaborative learning strategies on young children: an experimental study. International Journal Of Instructional Media, 38(4), 351-358. 